\title{
Mimicking the First Step of RNA Splicing: An Artificial DNA Enzyme Can Synthesize Branched RNA Using an Oligonucleotide Leaving Group as a 5'-Exon Analogue
}

\author{
Rebecca L. Coppins and Scott K. Silverman*
}

Department of Chemistry, University of Illinois at Urbana-Champaign, 600 South Mathews Avenue, Urbana, Illinois 61801

\section{Experiment with radiolabeled $\mathrm{R}$ for $\mathbf{0 T}$ and $\mathbf{0 M}$ to confirm the reaction products}

A

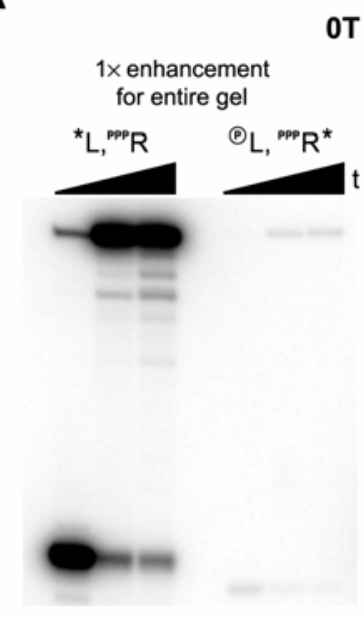

OT substrate

enhancements optimized to allow comparison of band positions

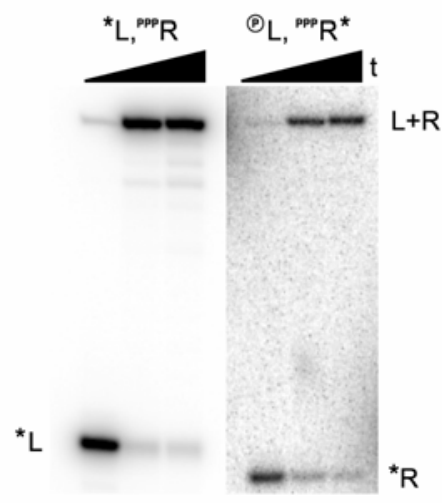

B

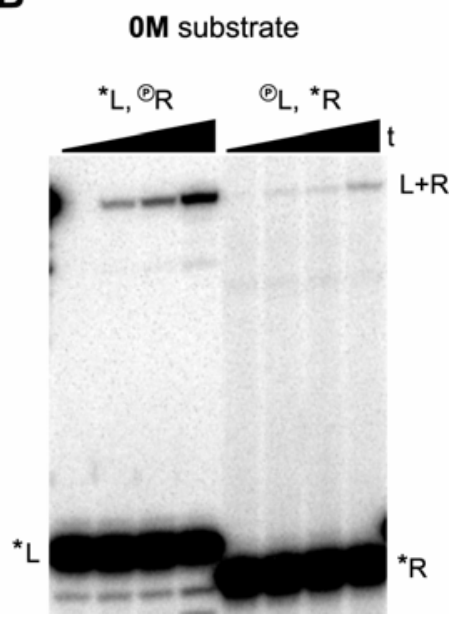

Figure X1. The 7S11-mediated ligation reactions with $\mathbf{0 T}$ and $\mathbf{0 M}$ right-hand (R) substrates, repeated using radiolabeled R instead of radiolabeled L. For both $\mathbf{0 T}$ and $\mathbf{0 M}$, the $\mathrm{L}+\mathrm{R}$ product band migrated at the same position regardless of whether $\mathrm{L}$ or R was radiolabeled. Either the L or R substrate was ${ }^{32} \mathrm{P}$-radiolabeled $\left({ }^{*}\right)$ as indicated. The circled P denotes 5 '-monophosphorylation with nonradioactive ${ }^{31} \mathrm{P}$; the designation PPP denotes a 5'-triphosphate. (A) Reactions of $\mathbf{0 T}(t=0$, 20, and 180 min). The radiolabeled $\mathbf{0 T} \mathrm{R}$ substrate was prepared by in vitro transcription with $\alpha-{ }^{32} \mathrm{P}-\mathrm{CTP}$ and was therefore of lower specific activity than the radiolabeled L substrate, which was prepared using $\gamma-{ }^{32} \mathrm{P}-\mathrm{ATP}$ and T4 PNK. The original gel exposure shown on the left side of the panel is shown again on the right with the PhosphorImager enhancements optimized to allow direct comparisons of the $\mathrm{L}+\mathrm{R}$ band positions. The exposure for the * $\mathrm{L}$ experiment is reduced by $10 \times$ and the exposure for the $* \mathrm{R}$ experiment is increased by $40 \times$ relative to the original gel exposure. (B) Reactions of $\mathbf{0 M}(t=0$, 10, 20, and $180 \mathrm{~min}$ ). The radiolabeled $\mathbf{0 M} \mathrm{R}$ substrate was prepared using $\gamma-{ }^{32} \mathrm{P}-\mathrm{ATP}$ and T4 PNK. The observation of the L+R product band at the same position for either location of the radiolabel (i.e., ${ }^{*} \mathrm{~L}$ or $* \mathrm{R}$ ) confirms that all nucleotides of both substrates are retained in the $\mathrm{L}+\mathrm{R}$ product. 


\section{Gel images for Figure 4}

$1 \times$ enhancement
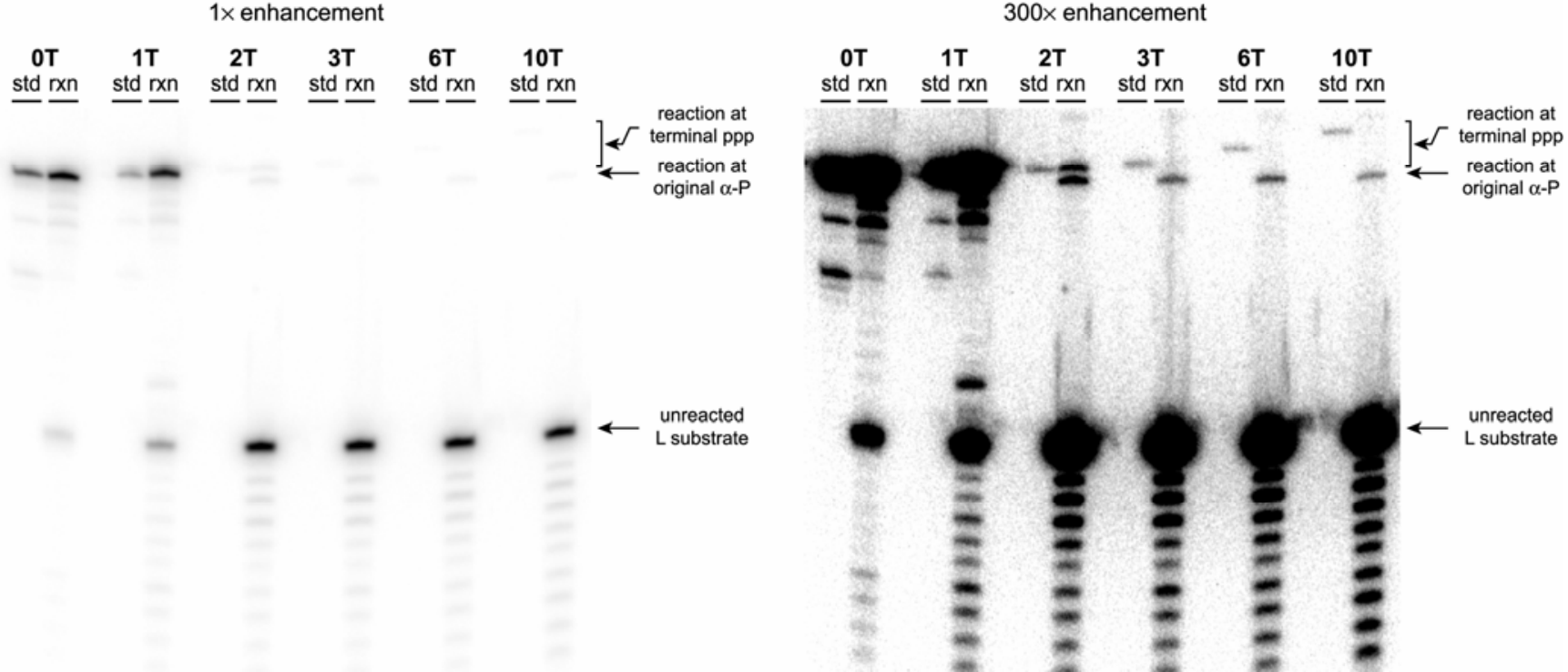

Figure X2. Fully unenhanced (1x) and fully enhanced (300x) versions of the gel image shown in Figure 4.

\section{Gel images for Figure 6A}

$1 \times$ enhancement

\begin{tabular}{|c|c|c|c|c|c|c|}
\hline OT 1T & $1 M$ & $1 \mathrm{H}$ & $2 \mathrm{~T}$ & $2 M$ & $2 \mathrm{H} \mathrm{OT}$ & \\
\hline$\underline{\text { std }} \underline{\mathrm{xn}}$ & $\underline{\mathrm{rxn}}$ & $\underline{\mathrm{rxn}}$ & $\underline{r x n}$ & $\underline{r x n}$ & $\underline{\text { rxn std }}$ & reaction at \\
\hline
\end{tabular}
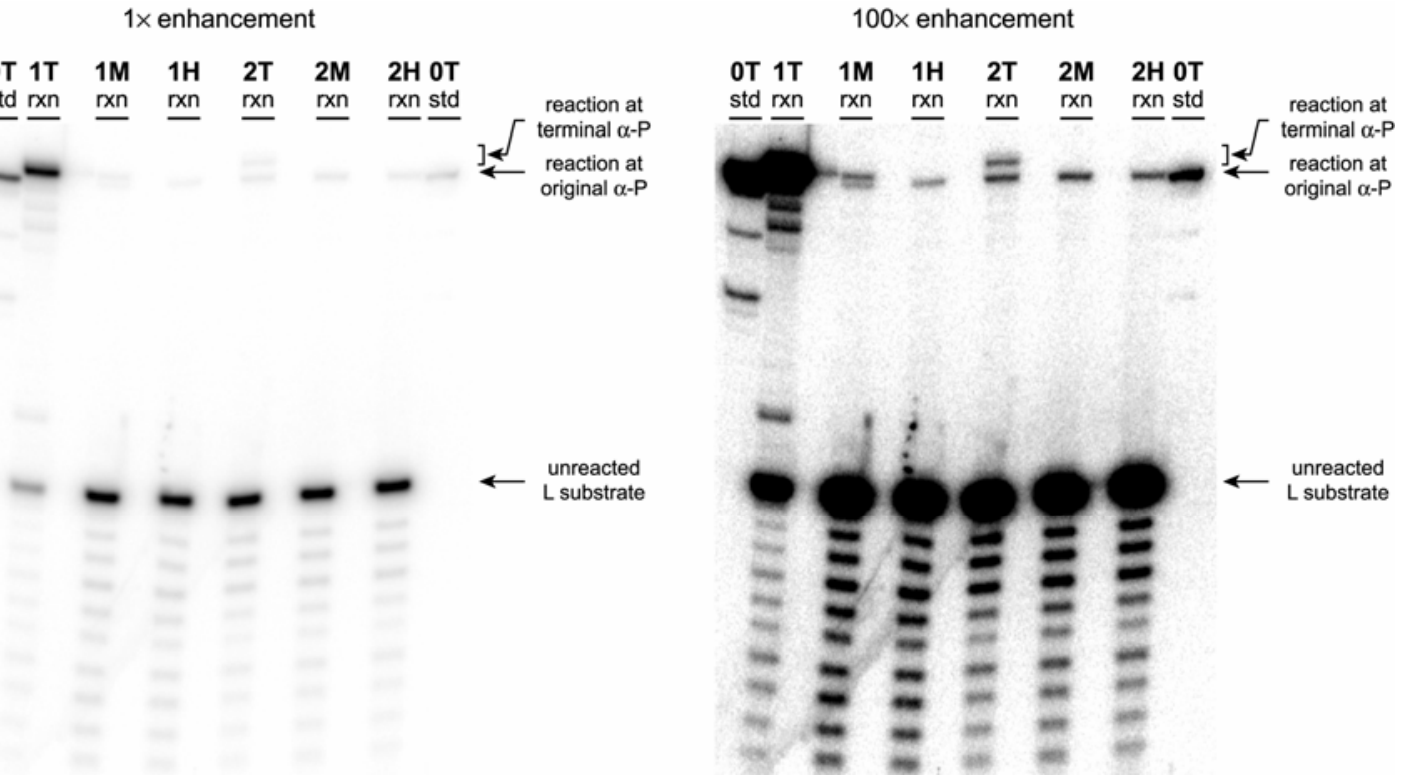

Figure X3. Fully unenhanced $(1 \times)$ and fully enhanced $(100 \times)$ versions of the gel image shown in Figure 6A. 